\title{
Assembly of RNPs: help needed
}

\author{
UTZ FISCHER $^{1}$ and ASHWIN CHARI ${ }^{2}$ \\ ${ }^{1}$ Department of Biochemistry, University of Wuerzburg, D-97074 Wuerzburg, Germany \\ ${ }^{2}$ Max-Planck-Institute for Biophysical Chemistry, D-37077 Goettingen, Germany
}

In 1968 the Nomura lab in Madison made an astonishing observation: when ribosomal proteins were mixed under appropriate conditions with $16 \mathrm{~S}$ rRNA, fully functional ribosomal 30S subunits were formed. Along with the subsequent total reconstitution of $50 \mathrm{~S}$ subunits, it was established that even entire ribosomes could be assembled in vitro from their constituents. Neither energy in the form of nucleoside triphosphates, nor other "helping factors," were required for this reaction. It was thus concluded that the structural information required for the formation of even complex macromolecules lies within its individual components itself and hence allows "self assembly." This notion was soon supported by many other labs, which managed to assemble macromolecular RNPs in spontaneous reactions, including the signal recognition particle (SRP), spliceosomal subcomplexes (U snRNPs) and nucleolar RNPs (snoRNPs), to name just a few. These findings were in full accordance with the observations of the Anfinsen lab in the 1950s that some polypeptide chains can fold spontaneously to functional three-dimensional proteins, postulating that the genetic blueprint itself, supplies structural information.

The emerging view derived from these studies, which were all performed in vitro was that only the production of biological macromolecules such as DNA, RNA and proteins required sophisticated enzymatic machineries and energy. Once they are made, however, their folding and/or unification to higher order structures can occur spontaneously and hence is determined solely by thermodynamic parameters but not by folding or assisting factors. While the concept of self-assembly (and folding) is certainly true for purified and diluted systems in vitro, it was soon realized that the situation in vivo is dramatically different. The cellular environment, in which these complexes are assembled, is highly crowded both in prokaryotic or eukaryotic cells. A major fraction of the interior of the cell is occupied with a large variety of different molecules, ranging from nucleic acids and proteins to metabolites. Such "molecular crowding" not only substantially perturbs diffusion-driven self-assembly, but also increases the likelihood of non-productive interactions (i.e.,

\footnotetext{
Corresponding author: utz.fischer@biozentrum.uni-wuerzburg.de Article and publication date are at http://www.rnajournal.org/cgi/doi/ 10.1261/rna.049791.115. Freely available online through the RNA Open Access option.
}

aggregation). Therefore, in contrast to what in vitro experiments had initially suggested, one could predict from these theoretical considerations that assembly processes in vivo may in general be guided by trans-acting "helper"-factors.

Two seminal observations in the late 1970s and early 1980s substantiated this view. The first was derived from experiments performed by Laskey and colleagues in the late 70 s, who studied the formation of nucleosomes. In the course of cell division, this process requires the massive production of histones, which are characterized by a high positive net charge and their subsequent unification with the negatively charged DNA. At the time it was well recognized that the efficient formation of nucleosomes in vitro required non-physiologically high salt concentrations. The Laskey lab found that cells employ a simple but efficient strategy to counteract this problem: They synthesize proteins, which sequester and safeguard histones from engaging in unwanted interactions and thus ensure nucleosome formation under physiological conditions. Appreciating the analogy to relationships amongst humans, they coined the term "chaperone" for these proteins. The Ellis and Hartl labs made the second important observation in the early 1980s. They recognized that other proteins, which bear functional similarities with the "assembly chaperone" described by Laskey, were necessary for the folding of proteins transported into organelles in a posttranslational manner.

Such findings were initially considered interesting, but rare examples rather than the rule for macromolecular assembly events. However, in the past 20 years, compelling evidence has accumulated showing that assembly (and folding) chaperones are more common than anticipated and probably influence many assembly reactions. In fact, it appears that the formation of even comparatively simple structures often requires a plethora of assembly factors. An extreme example in this respect is the assembly of spliceosomal snRNPs, which necessitates more assembly factors than parts to be assembled.

Why have assembly chaperones largely escaped our attention so far? One reason is certainly, that assembly chaperones constitute, in contrast to folding chaperones, a very diverse

(C) 2015 Fischer and Chari This article, published in RNA, is available under a Creative Commons License (Attribution-NonCommercial 4.0 International), as described at http://creativecommons.org/licenses/by-nc/4.0/. 
group of proteins with no common sequence signature. Hence, they are as such often not recognizable by conventional bioinformatics. As they typically act transiently in the assembly pathway and are absent from the mature complex, they are also intrinsically difficult to identify. Thus, strategies to arrest assembly pathways at pre-mature stages or time-resolved assembly studies combined with "state of the art technologies" are required to detect these factors.

The recent years of whole genome studies have enforced a view, in which (1) most cellular constituents do not act in isolation, but as part of complexes and (2) RNA protein (RNP) complexes comprise the largest class of such complexes. However, because the RNA and protein constituents of RNPs are synthesized in separate sub-cellular compartments (the nucleus and cytoplasm, respectively), precisely these particles impose a high logistical demand on accurate assembly in cells, Therefore, we predict that a large number of different assembly chaperones exist, which yet remain to be identified. They are likely to be involved in the biogenesis of many different RNPs but it is difficult to predict whether all RNPs require help during biogenesis or only certain "RNP classes." The complexity of an RNP appears not necessarily be an indicator as even simple RNPs have been shown to employ complex assembly systems. Abundant RNPs are probably more dependent on assembly chaperones than minor RNPs as they rely on the production of potentially toxic subunits in high amounts.

In our view, a major functional aspect of assembly chaperones has been overlooked thus far, which will certainly dominate research in the years to come. Taking the complexity of known assembly systems into account, it appears unlikely that RNA and protein components are released from their site synthesis and then encounter assembly factors by diffusion. It appears more likely that assembly chaperones actively engage with either the RNA polymerases or ribosomes, which synthesize the subunits of RNPs. It is to be envisaged that assembly chaperones accept their substrates either during synthesis itself or shortly after the termination of their synthesis. 

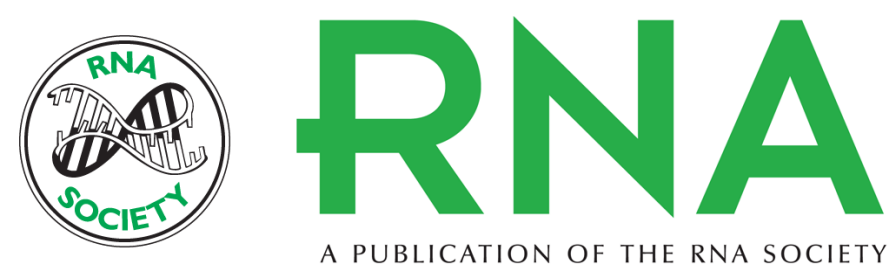

A PUBLICATION OF THE RNA SOCIETY

\section{Assembly of RNPs: help needed}

Utz Fischer and Ashwin Chari

RNA 2015 21: 613-614

Open Access Freely available online through the RNA Open Access option.

Creative This article, published in RNA, is available under a Creative Commons License

Commons (Attribution-NonCommercial 4.0 International), as described at

License http://creativecommons.org/licenses/by-nc/4.0/.

Email Alerting Receive free email alerts when new articles cite this article - sign up in the box at the Service top right corner of the article or click here.

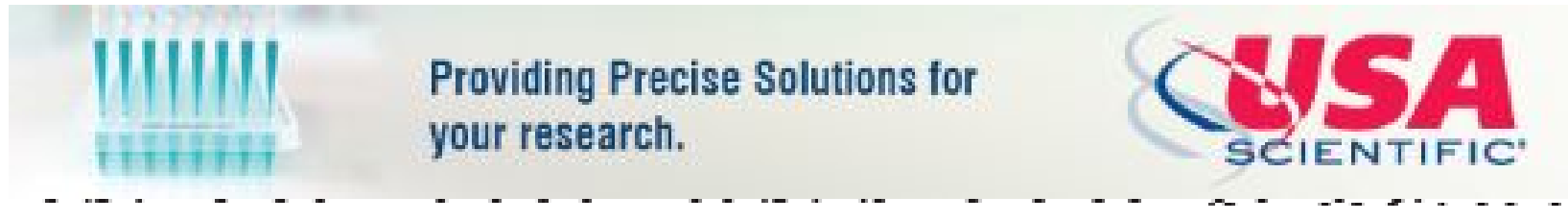

To subscribe to $R N A$ go to:

http://rnajournal.cshlp.org/subscriptions

(C) 2015 Fischer and Chari; Published by Cold Spring Harbor Laboratory Press for the RNA Society 